\title{
TEORIA DO ESTADO: \\ UMA PROPOSTA DE ABORDAGEM NO CONTEXTO DE GLOBALIZAÇÃO FINANCEIRA, CRISES E REFORMAS INSTITUCIONAIS. ${ }^{1}$
}

MURILO GASPARDO ${ }^{2}$

RESUMO: Neste ensaio debatemos qual é a contribuição da abordagem da Teoria do Estado para a compreensão do fenômeno estatal no contexto da globalização e de diferentes crises (sanitária, ambiental, econômica, política, social) que exigem reformas institucionais em relação às quais não há o mínimo consenso teórico, jurídico e político. Para tanto, nosso ponto de partida é a retomada das raízes da Teoria do Estado, de suas categorias e de seus pressupostos metodológicos fundamentais, considerando-se seus limites e os elementos que permanecem teoricamente operacionais. Em seguida, tratamos da ampliação do escopo da Teoria do Estado em face da condição em que se encontra o seu objeto no contexto da globalização financeira. Enfim, discutimos perspectivas metodológicas para a disciplina tendo como referência a ideia de "mapeamento institucional".

Palavras-Chave: Globalização financeira; Mapeamento institucional; Metodologia; Reformas institucionais; Teoria do Estado.

ABSTRACT: in this essay we discuss the contribution of the State Theory approach to the understanding of the state phenomenon in the context of globalization and different crises (sanitary, environmental, economic, political, social) that require institutional reforms in relation to which there is no minimum theoretical, legal and political consensus. Therefore, our starting point was the return to the roots of the State Theory, its categories and its fundamental methodological assumptions, considering its limits and the elements that remain theoretically operational. Then, we deal with the expansion of the scope of the State Theory considering the condition of its object in the context of financial globalization. Finally, we discuss methodological perspectives for the discipline with reference to the idea of "institutional mapping".

KEYWORDS: Financial globalization; Institutional mapping; Institutional reforms; Methodology; State Theory.

${ }^{1}$ A pesquisa que resultou neste artigo contou com apoio da FAPESP - Processo 2016/248754 .

2 Diretor da Faculdade de Ciências Humanas e Sociais da UNESP - Campus de Franca SP, onde é Professor Associado junto ao Departamento de Direito Público e ao Programa de Pós-graduação em Direito. Livre-docente em Teoria do Estado pela UNESP. Doutor, Mestre e Bacharel em Direito pela Faculdade de Direito da Universidade de São Paulo (USP). E-mail: murilo.gaspardo@unesp.br. 


\section{INTRODUÇÃO}

Dois grandes fenômenos da história recente reposicionaram o debate sobre o papel do Estado: a crise financeira global de 2008 e a pandemia de Covid 19. O Estado nunca deixou de desempenhar um papel relevante - o mercado capitalista é uma construção político-jurídica, assim como a política econômica neoliberal que forjou a globalização financeira. Entretanto, os referidos fenômenos e as respostas dadas pelo Estado, a exemplo do "Plano Biden", nos Estados Unidos da América, e do "Next Generation" da União Europeia, alteram substancialmente os parâmetros dessa discussão.

Diante disso, coloca-se a questão da atuação do Estado na regulação do mercado, no fomento às atividades econômicas, na garantia de empregos e renda, na proteção do meio ambiente, na implementação de políticas públicas que efetivem direitos sociais, como saúde, educação e assistência social, em contraposição ao discurso da austeridade e da redução do papel do Estado, e às reformas que, no caso brasileiro, desconstroem a estrutura do pacto político firmado na Constituição de 1988, quais sejam: Novo Regime Fiscal ("teto dos gastos públicos"), Reforma Trabalhista, Reforma da Previdência e Projeto de Reforma Administrativa.

Por sua vez, o enfrentamento dos dois fenômenos citados exige cooperação entre os Estados. Evidentemente, há grande desigualdade nas capacidades estatais em controlar a pandemia (veja-se a disparidade na evolução da vacinação entre os Estados mais ricos e os mais pobres), de garantir renda às pessoas mais afetadas pela crise, regular atividades financeiras e fomentar retomada da economia, porém os dois fenômenos são por natureza globais - assim como as variantes do novo Coronavírus, as crises financeiras também se propagam pelo mundo. Entretanto, quando mais a cooperação internacional é requerida, mais difícil ela se tornou (HALE, HELD \& YOUNG, 2013), seja pelo avanço do nacionalismo ou pela fragmentação, complexidade e incapacidade de organizações internacionais (Organização Mundial da Saúde, Fundo Monetário Internacional etc.) e transnacionais darem respostas às demandas a contento em seus campos de atuação.

Diferentes concepções sobre o papel e as formas de atuação do Estado em resposta a esses desafios, tanto em termos internos como nas relações internacionais, implicam diferentes alternativas de institucionalização jurídica do poder. A Teoria do Estado nasceu na virada do século XIX para o século XX com o propósito de descrever e explicar o fenômeno estatal a partir de uma perspectiva de conhecimento de síntese ou de totalidade, no qual a soberania e o direito como expressão do poder soberano representavam os elementos fundamentais da unidade do Estado. Neste ensaio debatemos qual seria a contribuição da abordagem da Teoria do Estado para a compreensão do fenômeno estatal no contexto da globalização e de diferentes crises (sanitária, ambiental, econômica, 
política, social) que exigem reformas institucionais em relação às quais não há o mínimo consenso teórico, jurídico e político.

As reflexões epistemológicas apresentadas neste ensaio foram desenvolvidas a partir do percurso metodológico de uma investigação sobre o déficit democrático da governança financeira global (GFG) e as possibilidades de reformas institucionais para sua democratização ${ }^{3}$, e amadurecidas nas discussões do Grupo de Pesquisa "Estado, Direito e Políticas Públicas". Naquela pesquisa, descrevemos, inicialmente, o fenômeno da globalização financeira e a estruturação de sua governança no que se refere ao processo político por meio do qual foi constituída e seus arranjos institucionais, os quais podem ser sumariamente caracterizados como uma complexa rede não-hierarquizada, com instituições de múltiplas formas e diferentes graus de institucionalização jurídica. Em seguida, analisamos o déficit democrático da GFG considerando-se, primeiramente, seu caráter de múltiplos níveis, pois ocorre no interior dos Estados (veja-se, por exemplo, a precariedade do controle democrático sobre os bancos centrais), entre os Estados (repercussões globais de decisões do Federal Reserve nos EUA e do Banco Central Europeu etc.), nas organizações internacionais e transnacionais (problemas de representatividade, transparência, accountability...) que compõem o sistema, e na atuação de poderosos agentes privados com enorme repercussão pública imune a quaisquer formas de controle democrático. Enfim, realizamos um "mapeamento" de alternativas no âmbito da produção teórica (Direito, Teoria Política, Economia Internacional), das próprias organizações internacionais e transnacionais (como Grupo dos 20, Fundo Monetário Internacional, Banco Mundial e Comitê da Basileia) e de organizações não-governamentais e movimentos sociais que atuam no âmbito da GFG.

Nosso ponto de partida neste trabalho será a retomada das raízes da Teoria do Estado, de suas categorias e de seus pressupostos metodológicos fundamentais, considerando-se seus limites e os elementos que permanecem teoricamente operacionais. Em seguida, trataremos da ampliação do escopo da Teoria do Estado em face da condição em que se encontra o Estado no contexto da globalização financeira. Enfim, discutiremos perspectivas metodológicas para a Teoria do Estado tendo como referência a ideia de "mapeamento institucional".

\section{TEORIA DO ESTADO: BREVE PANORAMA SOBRE SUAS RAÍZES E O CONTEXTO CONTEMPORÂNEO}

Desde o seu nascimento como disciplina científica no final do Século XIX e início do Século XX, com destaque para obra de Jellinek (1954), a definição do objeto e do método da Teoria do Estado é marcada por grandes controvérsias, com a contraposição entre o "formalismo jurídico" (KELSEN, 1973) e a "Sociologia do Estado" (HELLER, 1942).

3 Cf. Gaspardo, 2021. 
Jellinek (1954) definiu a Teoria do Estado como uma "ciência de síntese", que congrega as perspectivas jurídica e sociopolítica para um conhecimento geral sobre o Estado, situada epistemologicamente entre as ciências sociais explicativas (ciência do ser), e não "de aplicação", procurando distingui-la da Política (ciência do dever-ser), a qual seria baseada em "juízos de valoração" e estaria voltada para fins práticos. O método proposto pelo autor consiste na busca por elementos análogos entre os diferentes Estados para desenvolver classificações e elaborar conceitos unificadores, construindo tipos empíricos (método indutivo). Em suas análises, porém, predomina o viés jurídico-formal, o qual foi radicalizado por Kelsen (1973), que, em obra publicada originalmente em 1925, criticou a ideia de uma "ciência unitária do Estado", e defendeu a Teoria Geral do Estado como uma disciplina normativa, cujo objeto é o Estado enquanto "a totalidade da ordem jurídica ou uma ordem jurídica parcial". ${ }^{4}$

Heller (1942), por sua vez, em obra de 1934, ponderou que Jellinek e Kelsen, ao tentarem despolitizar a Teoria do Estado, acabaram por reduzi-la a "[...] pouco mais que a história e a construção de alguns conceitos de Direito Político", de maneira que resultou em uma "teoria pela teoria", ou uma "Teoria do Estado sem Estado", portanto, sem qualquer utilidade prática. Diante disso, o autor propôs outra concepção de Teoria do Estado, cujo objeto não seria o "Estado em geral", mas os Estados reais com suas especificidades, com um caráter prático, e em cuja produção do conhecimento não é possível a separação entre sujeito e objeto, por se tratar de uma "ciência cultural".

No Brasil, Reale (1960), em 1940, defendeu uma "doutrina culturalista realista do Estado e do Direito", apresentada como um "justo equilíbrio" entre as posições consideradas exageradas dos que, por um lado, "confundem o Estado com a própria realidade social", ou, por outro lado, "fazem abstração da sociedade, para só apreciar o mundo jurídico como um mundo puro de normas". Assim, para Reale (1960, p. 29-30), a autonomia científica da Teoria do Estado depende do conhecimento de seu objeto a partir de uma "tríplice perspectiva" (jurídica, sociológica e política), que seja capaz de conhecer essas três dimensões da realidade estatal unificadas pelo fenômeno do poder, o qual não pode ser compreendido por quaisquer desses prismas isoladamente.

Dallari (2013), em obra fundamental publicada pela primeira vez em 1971, segue uma linha muito próxima ao culturalismo realista de Reale, apresentando a Teoria Geral do Estado como "uma disciplina de síntese, que sistematiza conhecimentos" de várias outras disciplinas a fim de "buscar o aperfeiçoamento do Estado", o qual é concebido, simultaneamente, como "um fato social e uma ordem jurídica, que procura atingir seus fins com eficácia e com justiça". Ressaltamos, dentro dessa concepção, que a importância atribuída pela Teoria

\footnotetext{
${ }^{4}$ As traduções de citações literais de trabalhos publicados em Inglês e Espanhol foram realizadas livremente pelo autor.
} 
Geral do Estado aos elementos jurídicos para a compreensão de seu objeto é o que a diferencia da Ciência Política.

Nos anos 1990, Tojal (1997) denunciou a "crise de degenerescência de seus paradigmas epistemológicos" e defendeu que a Teoria do Estado conserva uma fundamental dimensão normativa, pela centralidade do elemento jurídico na constituição de seu objeto, enquanto fator de institucionalização das relações políticas, mas deveria ser compreendida como uma nova ciência social, de natureza discursiva, não empírica. A Teoria do Estado deveria abandonar a pretensão irrealizável de um conhecimento total sobre o seu objeto, bem como sua idealização axiológica, desenvolvendo uma pesquisa interdisciplinar, não formalista, na qual o Estado é considerado em sua dinâmica social. Enfim, tratando-se de um objeto de natureza cultural, a neutralidade do conhecimento sobre ele seria impossível. Isso porque, o conhecimento é condicionado pelos valores e interesses inerentes ao pesquisador e ao espaço geopolítico e social que ocupa. (B. S. SANTOS, 2010).

Nessa linha, Stuchi (2018), retomando ideias de Heller, salienta a inadequação da aplicação de concepções de Estado e soberania formuladas para a compreensão dos Estados centrais para a análise da realidade estatal periférica e semiperiférica. Assim, a autora (2018, p. 141) defende uma teoria realista do Estado, a qual deve considerar sua posição na "economia-mundo", para compreender o exercício real do poder e "[...] os fatores históricos que determinam ou influenciam o conteúdo do direito, a estruturação do ordenamento jurídico e os limites de imposição do próprio direito no âmbito nacional".

Concluindo este breve histórico, destacamos a posição de Bucci (2018, p. 2931), para quem a Teoria do Estado é uma disciplina de base jurídica, cujo objeto, em apertada síntese, é o estudo dos "[...] mecanismos institucionais que tornam possível o exercício do poder e seu controle em uma ordem institucionalizada", o que exige a "[...] compreensão das relações entre o direito e a política, especialmente no que se refere à criação do direito, isto é, a tradução de demandas geradas na sociedade em construções jurídica e formalmente estruturadas". Assim, a Teoria do Estado se diferencia tanto do Direito Constitucional, que tem como campo o direito positivo, como da Ciência Política, cujo objeto encontra-se nas "relações entre o poder e a sociedade". Já o método da Teoria do Estado consiste, para Bucci (2018, p. 71), em "[...] observar criticamente práticas de contato entre o poder e o direito, analisá-las, produzir a condensação em esquemas teóricos e representação cognitiva, traduzi-las em modelos jurídicos, em que as normas e instituições são as peças básicas".

Considerando-se as raízes da Teoria do Estado, a constância da ideia de crise em seu desenvolvimento no exterior e no Brasil, bem como as características da globalização contemporânea na qual o Estado está inserido, destacamos, por um lado, a permanência de alguns elementos centrais que nos possibilitam a referência a uma mesma disciplina na segunda década do século XXI e, por outro 
lado, a exigência de transformações na própria concepção de seu objeto e na construção de novas perspectivas de abordagens metodológicas. Permanece como objeto da Teoria do Estado a institucionalização jurídica do poder, ou seja, o estabelecimento, por meio de normas jurídicas socialmente reconhecidas (constituições, leis, decretos, decisões judiciais, tratados etc.) de estruturas e processos que regem o exercício do poder, prescrevem critérios e procedimentos para a mediação de conflitos políticos, vedam ou estimulam comportamentos (como o respeito aos resultados eleitorais pelos derrotados em função da expectativa normativamente garantida de que, depois de determinado período, terão a oportunidade de tentar vencer as eleições e conquistar o poder). Essas instituições jurídico-políticas podem tanto conferir reconhecimento formal e estabilização à distribuição de poder de fato em um dado momento histórico, como introduzir processos que alterem o equilíbrio de poder (veja-se a relação de causalidade observada entre a universalização do sufrágio e a ampliação dos direitos sociais). O Estado continua a ser a expressão maior da institucionalização jurídica do poder, porém não é a única em face do policentrismo político característico da contemporaneidade, o que remete ao problema da permanência (ou não) da unidade enquanto características definidoras do Estado ${ }^{5}$. É preciso também ponderar em que medida a soberania continua a ser uma categoria válida para a compreensão do fenômeno estatal, tanto quando consideramos o fenômeno da globalização financeira, como também as especificidades dos Estados periféricos e semiperiféricos na economia-mundo.

A centralidade do estudo institucional não se deve a um entendimento de que as instituições definiriam os resultados dos processos políticos e de que os fatores reais de poder não seriam relevantes. Porém, sem instituições, o que resta é a vontade dos governantes e demais agentes poderosos, com os riscos do arbítrio e do recurso à violência como meio tanto para a imposição da vontade dominante como de resistência. ${ }^{6}$ (WALDRON, 2013, p. 1-2). Referindo-se à Teoria Política, Waldron (2013, p. 5-10) ressalta que sua tarefa primeira não seria o estudo nem das virtudes nem das instituições, mas sim dos "objetivos e ideais que dirigem nossa política". Todavia, como há grande divergência sobre quais seriam esses fins e ideais, o autor retoma o caráter fundamental da análise das instituições, pois

\footnotetext{
${ }^{5}$ Ver artigo de Maria Paula Dallari Bucci neste dossiê.

${ }^{6}$ Em panorama sobre o desenvolvimento da Teoria Política, Waldron (2013, p. 21-22) assinala que “[...] o estudo das instituições políticas tem sido o foco da teoria política desde Aristóteles. No início da tradição moderna, temos Hobbes tratando da estrutura da soberania e o desafio absolutista ao 'rule of law'. Há John Locke com sua paradoxal combinação entre supremacia legislativa e limitação legislativa e suas perspectivas de separação de poderes. Nós temos Rousseau com as diferenças entre a produção democrática do direito e o governo democrático, e seu repúdio à representação, pelo menos quando considera a primeira dessas funções. E, em oposição a Rousseau, temos Madison, claro, sobre as maneiras pelas quais uma república popular pode se estabelecer em um país de grande extensão sem ficar preso nas armadilhas da democracia direta".
} 
são elas que definem os processos e regras por meio dos quais os conflitos políticos são resolvidos sem que degenerem em processos violentos. Ele sugere, então, o conhecimento comparativo sobre as instituições em seus detalhes operacionais como campo da Teoria Política normativa, e não apenas da Ciência Política empírica, pois, ainda que se parta de elementos empíricos, sempre há escolhas nos desenhos institucionais, orientadas por valores e posições políticas.

Essas considerações de Waldron sobre a Teoria Política se aproximam da perspectiva da Teoria do Estado - tanto a centralidade da análise sobre as instituições, como a abordagem metodológica de conhecimento comparativo de seus detalhes operacionais, considerando-as na perspectiva empírica e dos valores que as orientam. A diferença fundamental da Teoria do Estado em relação à Teoria Política normativa é seu domínio sobre as ferramentas jurídicas, visto que, originariamente, é uma disciplina jurídica ${ }^{7}$.

A realização de comparações para a formulação de classificações e conceitos unificadores ("tipos empíricos") encontra-se, desde Jellinek (1954), no centro da orientação metodológica da Teoria do Estado, o que permanece no contexto contemporâneo, assegurando-se a continuidade da disciplina. Entretanto, a complexidade das formas, papéis, funções, relações e modelos institucionais com os quais nos deparamos hoje torna muito difícil a elaboração dessas tipologias, revelando-se mais promissor o exercício do mapeamento da diversidade institucional, inclusive e de maneira particularmente interessante, o mapeamento de alternativas de reformas institucionais.

Ainda da perspectiva metodológica, como já assinalado, a contribuição da Teoria do Estado para a compreensão de seu objeto tem como exigência a busca da produção de um conhecimento realista sobre o Estado, não baseado em categorias idealizadas, e que considere as especificidades histórico-políticas de cada Estado. Em segundo lugar, reconhece-se a impossibilidade de um conhecimento neutro sobre o Estado, porém isso não isenta o pesquisador do rigor analítico e da análise sistemática que considere todos os fatores relevantes para o problema. Enfim, a complexidade do objeto requer a substituição da ideia de uma "ciência de síntese" por uma mais modesta de pesquisa interdisciplinar, na qual

\footnotetext{
7 Podemos também estabelecer um diálogo entre a concepção que de Teoria do Estado que adotamos e o enquadramento que Dryzek, Honig e Philip (2006, p. 4-6) estabelecem para a Teoria Política, considerada como um "esforço interdisciplinar" situado entre os conceitos universais da Filosofia Política e o trabalho empírico da Ciência Política, e cuja tarefa consiste em "teorizar, criticar e promover o diagnóstico sobre normas, práticas e organização da ação política no passado e no presente", com um enfoque mais interpretativo. Para tanto, os "[...] teóricos da Política se valem de estudos empíricos da Ciência Política, da Economia, da Sociologia e do Direito para informar suas reflexões". Além disso, a maior parte da Teoria Política apresenta um componente normativo essencial, independentemente das perspectivas metodológica e política adotadas. Aqui também uma diferença fundamental da Teoria do Estado é seu domínio sobre as ferramentas jurídicas.
} 
o enfoque prevalecente é o jurídico-institucional, mas em permanente diálogo com outras perspectivas analíticas, em particular a política e a econômica.

Nas duas seções subsequentes aprofundaremos esse debate, respectivamente abordando a ampliação do escopo do objeto da Teoria do Estado e a proposta de abordagem metodológica baseada na ideia de "mapeamento institucional".

\section{A AMPLIAÇÃo Do ESCOPO DA TEORIA DO ESTADO}

O âmbito de abrangência da Teoria do Estado, no contexto contemporâneo, não deve se limitar às instituições e relações de poder delimitadas pela soberania e pelas fronteiras estatais, mas deve abranger também as interações do Estado na esfera global, como é o caso da mundialização financeira e de sua governança. Isso exige que se considere, além das interações entre o direito e a política, as de ambos com a economia. Em alguma medida, essa perspectiva já tem aparecido em obras de referência da Teoria do Estado.

O mais tradicional manual brasileiro de Teoria do Estado, escrito por Dallari (2013), já abordava a posição do Estado na Ordem Internacional, destacando que o mundo é uma sociedade de Estados, com imperfeita integração entre os âmbitos jurídicos e o político, dedicando um capítulo ao tema, com destaque para as origens e o papel da Organização das Nações Unidas (ONU). A globalização, a resposta da regionalização e seus impactos sobre a soberania constituíram o objeto da Tese de Titularidade em Teoria Geral do Estado na Faculdade de Direito da Universidade de São Paulo de Lewandowski (2002), na qual o autor desenvolveu uma análise histórica descritiva e explicativa sobre os fenômenos, com importante diálogo com a perspectiva econômica, em especial a dinâmica da "globalização financeira". Em obra de referência mais recente, Ranieri (2013) trata do "Estado internacionalizado", avançando para além das organizações internacionais, ao considerar os fenômenos da globalização e da regionalização (constituição de vários níveis de governo), com seus impactos sobre a soberania estatal, a formação de uma "aldeia global", as crises financeiras de 2008 e 2012 etc.. A autora insere entre os cenários e desafios futuros para os Estados a ideia de uma responsabilidade comum, que implicaria uma significativa revisão da concepção de soberania, além de temas como o constitucionalismo e a cidadania global, mencionando brevemente o problema do déficit democrático nas relações internacionais.

Partindo desses trabalhos precedentes, propomos o alargamento da abrangência da Teoria do Estado por meio da consideração em maior profundidade das interações do Estado na governança global e, em particular, ao problema da democracia na esfera global.

Como o exercício da soberania estatal (e, portanto, da produção do direito e das políticas públicas), por um lado, é considerado legítimo apenas se ocorrer em bases democráticas e, por outro, é condicionado pela globalização, a democracia em sua dimensão global constitui um campo por excelência para o conhecimento 
sobre a institucionalização das relações políticas pelo direito. Isso se aplica de forma particularmente relevante à governança financeira (e monetária) global, pois o controle sobre a moeda e as finanças, ao lado do monopólio da produção do direito e do uso legítimo da força, é um elemento central de expressão da soberania do Estado. Além disso, ponderamos que o fato de pensarmos a democracia na dimensão global não significa que o Estado tenha perdido sua centralidade. Enfim, a divisão dos objetos entre diferentes disciplinas existe para facilitar o trabalho científico, sendo a interdisciplinaridade recomendável (e mesmo indispensável) quando a melhor compreensão de determinado problema assim o exigir.

Portanto, a mundialização financeira e as instituições responsáveis por sua governança são um objeto pertinente ao âmbito da Teoria do Estado. Inclusive porque ainda hoje as principais instituições responsáveis pela governança financeira são expressão direta da soberania estatal (ministérios de finanças ou similares e bancos centrais) ou foram constituídas por expressão de seu consentimento (Fundo Monetário Internacional e Banco Mundial), às quais se somam organizações menos formais e de caráter rizomático, como o Comitê da Basileia de Supervisão Bancária e o Comitê de Estabilidade Financeira. Mais do que um objeto possível da Teoria do Estado, há um importante ganho analítico no estudo da governança financeira global a partir dessa sede epistemológica, tanto pelo domínio da disciplina sobre o conhecimento do elemento fundamental de edificação de suas instituições - o direito, como pelo acúmulo de estudos da disciplina sobre duas categorias analíticas centrais para sua análise: soberania e democracia.

Para tanto, propõe-se um diálogo mais próximo da Teoria do Estado com a Economia Política, pois o capitalismo é a força mais poderosa na determinação das relações políticas, da configuração do Estado e do funcionamento da democracia $^{8}$. Não é possível estudar como as democracias realmente funcionam sem considerar devidamente como o capitalismo as limita e conforma, o poder exercido por grupos de interesse e grandes corporações. (ELKIM, 2006). A Economia Política Internacional", por sua vez, refere-se à "maneira como a economia mundial é organizada politicamente", ou à "conexão entre política e

\footnotetext{
8 Embora pareçam campos antagônicos (uma trataria de fatos e a outra de normas, a partir de diferentes metodologias - observação empírica e julgamentos morais), a Economia Política Internacional e a Teoria Democrática Normativa (outra disciplina importante em nossa formulação) podem atuar de forma muito próxima e articulada na compreensão da maneira como a globalização afeta a autonomia dos Estados e as democracias liberais, aproveitando reciprocamente suas reflexões. Isso porque, como já destacado, não existe análise empírica neutra de fenômenos políticos e econômicos, e a teoria (inclusive a normativa) não é independente do contexto histórico concreto no qual está inserida, voltando-se sempre para algum propósito: a manutenção ou a transformação da ordem social existente. (AGNÉ, 2011).

${ }_{9} \mathrm{P}$ ara uma análise sobre diferentes perspectivas da Economia Política Internacional e as influências de Gramsci, Polanyi, Strange e Cox no seu desenvolvimento, cf. Belfrage e Worth, 2012.
} 
economia nas relações internacionais", tendo como fundamento a compreensão de que a existência de qualquer sistema econômico depende do quadro político que lhe é subjacente - portanto, das relações entre os Estados, de suas condições de participação das disputas de poder, e das diferentes forças políticas que interagem nos âmbitos nacional e internacional. Assim, "a economia mundial e o sistema político internacional não podem ser analisados adequadamente de forma separada". Exige-se, pois, "a superação das distinções artificiais entre a economia e a política, o âmbito doméstico e o internacional". (HETTNE, 1995, p. 1-6).

\section{O MÉTOdo da TEORIA do ESTAdo: A PROPOSTA DE ABORDAGEM DO MAPEAMENTO INSTITUCIONAL}

Como uma das abordagens metodológicas possíveis para a Teoria do Estado, especialmente interessante em um contexto de múltiplas crises que demandam reformas institucionais, propomos o mapeamento, a análise e o desenvolvimento de alternativas de desenhos institucionais (UNGER, 1996, 1999, 2001, 2015) a partir da identificação de falhas nas instituições existentes e do estudo dos processos causais que as provocaram (WIENS, 2012), conforme critérios políticos determinados. Quais são as alternativas de reformas institucionais disponíveis em resposta aos múltiplos desafios do Estado contemporâneo (democracia, globalização, políticas públicas garantidoras de direitos etc.)? A partir de quais diagnósticos sobre os problemas do Estado que tais alternativas foram formuladas? Quais valores e interesses orientam tanto os diagnósticos como a formulação das alternativas?

Tratando da Teoria Política, Wiens (2012, p. 45-67) propõe uma abordagem metodológica que denomina de "clinical institutional theory". $\mathrm{O}$ autor explica que sua proposta contrapõe-se ao método mais usual de prescrição de instituições, de acordo com o qual se busca a elaboração de projetos institucionais para a superação ou mitigação das injustiças vigentes a partir de "teorias normativas ideais" ("princípios de regulação") formuladas pela Filosofia Política. Parte-se, pois, de modelos idealizados e contrapostos às instituições e condições políticas existentes. Já a "clinical institutional theory" tem como ponto de partida a identificação de falhas nas instituições existentes (descrição) e os processos causais que as provocaram (diagnóstico). Assim, a prescrição de soluções não é orientada por um ideal de justiça, mas pelas situações de injustiça realmente existentes e pelas insatisfações com as instituições. Não há um plano preexistente, ele é definido a partir da análise sobre as falhas. $\mathrm{O}$ autor adverte, porém, que os objetivos do desenho institucional pretendido não são apenas tecnicamente apurados, mas também politicamente determinados. Aliás, o posicionamento político interfere na própria identificação das falhas - a compreensão da desigualdade socioeconômica como um problema, por exemplo, depende da posição em que o indivíduo ou uma coletividade se encontram na sociedade. $\mathrm{O}$ autor divide os problemas enfrentados por sua perspectiva metodológica em duas 
categorias: "de arquitetura" e "de engenharia". Aqueles remetem à organização criativa de diferentes componentes para atender a determinadas funcionalidades, ou como "diferentes composições institucionais incorporam distintos conjuntos de valores". Estes, por sua vez, referem-se às questões técnicas que tais desenhos envolvem (a aplicação de princípios científicos para determinar quais requisitos as instituições devem preencher para suportar as diferentes pressões e restrições às quais são submetidas no desempenho de suas funções). Ambas as perspectivas são indispensáveis e articuladas na projeção de instituições. Todavia, o enfoque predominante tem sido nos "problemas de arquitetura", e o descuido com as "questões de engenharia" tem como consequência a disfuncionalidade dos projetos de reforma institucional (instituições que não são efetivas e estáveis). Assim, seria necessário considerarmos adequadamente as duas abordagens na análise e elaboração de projetos institucionais, de maneira que sejam descartadas tanto as hipóteses que se se afastam demasiadamente dos ideais normativamente estabelecidos a partir de determinados valores, como as que se revelem disfuncionais (ou pouco plausíveis/viáveis), o que também possibilitaria antecipar potenciais fragilidades a fim de efetuar correções. Trata-se, pois, de solucionar problemas realmente existentes, de forma temporária, contingente e experimental, e não de superar a distância entre a realidade e modelos ideais.

Essa proposta traz importante contribuição para o alargamento de uma perspectiva metodológica da Teoria do Estado de caráter mais analítico, tal como a defendida por Bucci $(2018$, p. 71$)$ - a observação crítica das "práticas de contato entre o poder e o direito", e a partir disso, a produção de "esquemas teóricos" explicativos e modelos jurídicos -, bem como para o enfoque mais prescritivo que propomos - o mapeamento, a análise e o desenvolvimento de alternativas de reformas institucionais. É a partir da identificação das "falhas" das instituições, tanto em termos de "arquitetura" como de "engenharia", que se deve mapear as alternativas para reformá-las e avaliar criticamente, inclusive, os projetos em discussão nas instituições políticas, seja, por exemplo, no âmbito do Congresso Nacional, ou de organizações de governança global e transnacional.

No exemplo da aplicação de tal proposta de abordagem metodológica ao campo da governança financeira global, buscamos, em primeiro lugar, identificar as características ou dimensões de seu déficit democrático e quais são suas causas político-institucionais (relações de poder e desenho institucional), em suas relações com outras (de natureza econômica e ideológica, por exemplo) e, a partir desse diagnóstico, mapear as possíveis alternativas de reforma institucional para mitigação (ou superação) desse déficit. Não se trata, porém, de uma operação meramente técnica, a posição política (interesses, ideologia etc.) também determinam o processo de mapeamento. Na identificação dos problemas e no mapeamento das possíveis soluções, as questões de arquitetura podem ser orientadas por diferentes valores, como a estabilidade financeira, a democracia e a redução de desigualdades. As questões de engenharia remetem às forças 
políticas envolvidas (por exemplo, Estados, companhias financeiras, organizações não- governamentais, comunidade acadêmica, mídia, partidos etc.), à dinâmica da economia e à complexidade técnica do campo de pesquisa.

A proposta apresentada por Wiens (2012) pode ser considerada uma abordagem de projeção de instituições classificada como "problem-solving theory" no sentido de que parte do diagnóstico de problemas institucionais determinados a serem solucionados e não de uma crítica global da sociedade. Porém, o autor não defende uma abordagem tecnicista, mas sim politicamente orientada: o diagnóstico sobre os problemas de arquitetura e de engenharia das instituições e a formulação de alternativas sempre apresentam fundamentos políticos. Os pontos essenciais da abordagem são a consideração dessas duas dimensões analíticas (arquitetura e engenharia) e a adoção dos problemas e não das teorias normativas como ponto de partida para a formulação de alternativas de reformas institucionais. Há, pois, possibilidade de diálogo com as perspectivas denominadas críticas.

De acordo com Cox (1995), uma "problem-solving theory" objetiva fornecer orientações para a correção de disfuncionalidades da ordem estabelecida, considerada boa em seu conjunto, enquanto que as "teorias críticas" preocupamse com a transformação da ordem existente, com estratégias para mudanças de caráter estrutural. As primeiras tratam de problemas específicos, já as últimas consideram a ordem em sua perspectiva global - mesmo quando se voltam para questões determinadas, o fazem em vista do quadro completo. Esta seria histórica e aquela a-histórica. As teorias críticas perderiam em precisão para as "problemsolving theories", as quais, todavia, basear-se-iam na falsa premissa de que a ordem vigente pode ser reparada. Assim, estas teriam propósito conservador, enquanto aquelas almejariam a transformação. O autor ressalta que, não obstante as teorias críticas contenham um elemento utópico, este é condicionado pela compreensão dos processos históricos, de maneira que alternativas improváveis são rejeitadas.

Da perspectiva da teoria crítica, as instituições são consideradas reflexos das relações de poder prevalecentes e instrumentos para estabilização e perpetuação da ordem estabelecida, prestando-se, pois, à consolidação de uma "hegemonia" (em conjunto com as relações materiais e a ideologia), à minimização da necessidade de recurso à força para o exercício da dominação, pois os mais fracos a aceitam como legítima. (COX, 1981).

Além disso, a adoção de uma perspectiva crítica significa a rejeição da crença em uma verdade objetiva única, da rígida distinção entre fatos e valores. Não se trata apenas de desconstruir o conhecimento e as práticas dominantes, mas também de construir um conhecimento alternativo sobre o que existe, bem como sobre o que deveria existir para transformar as relações de poder, ou seja, "utopias fundamentadas", concebidas como "alternativas que nunca existiram", mas que podem existir no futuro, a partir da identificação de tendências históricas. (MITTELMAN, 2011). 
Se da perspectiva da teoria crítica derivar a transformação global do sistema econômico como pré-condição para quaisquer mudanças institucionais que promovam valores como democracia e justiça social, ela não oferecerá contribuição para a formulação e o desenvolvimento de propostas de reformas institucionais, restando o caminho da revolução. Em função disso, tais teorias costumam se deparar com a indagação acerca da viabilidade do que propõe, da ausência de propostas alternativas minimamente factíveis, o que enfraquece seu próprio potencial $\mathrm{crítico}^{10}$. Há, entretanto, a possibilidade de se pensar em reformas incrementais criticamente orientadas ${ }^{11}$.

O problema da viabilidade, situado entre a possibilidade e a probabilidade, não precisa ser necessariamente abordado de forma binária ("tudo ou nada"), mas também escalar, variando conforme as condições fáticas de determinado momento, as restrições de caráter econômico, institucional e cultural existentes. (LAWFORD-SMITH, 2013). Além disso, as transformações têm como obstáculos tanto a resistência daqueles que são favorecidos pela ordem estabelecida como a crença dos demais de que seriam impossíveis em razão dos fracassos históricos das alternativas ao sistema vigente e ao desespero dos indivíduos em razão de suas condições de vida. Assim, a viabilidade de um projeto de transformação social também depende da capacidade de convencimento de que é possível, o que "[...] não implica engajar-se em um otimismo fácil que ignore as reais restrições para a mudança". Portanto, não se pode confundir viabilidade com a restrição das opções políticas disponíveis. (CALLINICOS, 2000, p. 128).

Isso se aplica, por exemplo, ao campo da governança financeira global. Há diferentes modelos de democracia (HELD, 2006), ou diferentes formas institucionais ótimas para concretização do conceito de democracia para cada um dos diferentes níveis de governança (local, nacional, regional/global) e momentos da história. Em meio à sua grande diversidade, podemos classificar esses modelos institucionais em três grandes categorias: (1) democracia direta; (2) democracia representativa; e (3) democracia deliberativa. $O$ modelo institucional de democracia para o âmbito da governança financeira global deve ser adequado às especificidades deste nível. Coloca-se, a esse propósito, o problema da possibilidade racional do modelo, o qual não se confunde com a questão da possibilidade política, que é contingente e pertencente ao campo da luta política - o que não diminui a importância dos "problemas de engenharia". Assim, não

${ }^{10}$ Bosweel e Chase-Dunn (2006, p. 329) fazem uma advertência importante a propósito do pensamento utópico: ele pode servir como um recurso para os que não são capazes de pensar em transformações efetivas e possíveis das instituições existentes, ao mesmo tempo que pode deslegitimar esforços efetivos para promover a mudança social, por considerá-la impossível. Assim, os autores defendem a estratégia de se pensar nos próximos passos plausíveis e atingíveis dentro de um contexto histórico determinado.

${ }^{11}$ BRUNET, Emiliano. Estado, Poder Político e Direito em uma Época de Mudanças: por que ler Gramsci? Revista Estudos Institucionais. V.7, N.3, 880-907, set./dez., 2021. 
parece logicamente possível a ideia do voto direto em assembleias como modelo institucional de democracia no campo da governança financeira global. Por outro lado, também não seria logicamente coerente um modelo institucional que esvaziasse completamente o conteúdo do conceito com proclamações genéricas sobre transparência, consultas e accountability, restando apenas o rótulo "democracia" - isso afastaria demais o desenho institucional dos valores democráticos ("problemas de arquitetura"). Há que se procurar alternativas logicamente possíveis, adequadas à natureza diagnosticada do déficit democrático da governança financeira global e capazes de convencer e mobilizar as forças políticas relevantes.

Entendemos que tanto a abordagem de problem-solving theory como de teoria crítica são cabíveis no âmbito da Teoria do Estado e úteis ao mapeamento de alternativas institucionais, trata-se de uma questão de escolha metodológica politicamente informada - não há pesquisa neutra em Teoria do Estado. A posição que adotamos é a de mapeamento de alternativas de reformas institucionais para a solução de problemas orientada pela crítica global ao sistema e com o propósito de, pela via incremental, promover sua transformação radical. Há momentos históricos mais propícios para transformações globais, outros em que apenas reformas incrementais e cumulativas se mostram viáveis para a solução de determinados problemas e a concretização de certos valores.

Nesse sentido, Boaventura de Sousa Santos (2003, p. 8) destaca que, embora atravessemos uma época na qual as duas estratégias modernas de transformação social (revolução e reformismo jurídico) se encontram em crise, bem como em que o direito instrumentaliza e legitima a dominação dos interesses e grupos hegemônicos, ele também pode desempenhar um papel emancipatório, desde que seja reinventado de forma a adequar-se às reivindicações normativas dos grupos sociais subalternizados e de seus movimentos, inclusive daqueles que integram as lutas globais de tipo contra-hegemônico, que atuam por alternativas ao modelo neoliberal de globalização. Assim, apresenta-se a tarefa científica e política de “[...] reinventar o direito para lá do modelo liberal e demo-socialista e sem cair na agenda conservadora - e, mais ainda, como fazê-lo de modo a combater esta última de modo mais eficaz". Para tanto, Boaventura de Sousa Santos (2011) propõe uma abordagem metodológica que denomina de "sociologia das emergências" "12, a qual também não consiste em conceber abstratamente soluções idealizadas, mas sim em identificar tendências que possam ser expandidas (inclusive nas situações de crise), interpretando de "maneira expansiva" as demandas e ideias de movimentos de resistência ao neoliberalismo ${ }^{13}$. Por essa

${ }^{12}$ A sociologia das emergências compreende uma "amplificação simbólica de sinais, pistas e tendências latentes que, embora dispersas, embrionárias e fragmentadas, apontam para novas constelações de sentido tanto no que respeita à compreensão como à transformação do mundo". (B. S. SANTOS, 2010, p. 42).

${ }^{13}$ Essa proposta de Boaventura de Sousa Santos (2011, p. 16-17, 21-22) enquadra-se em seu projeto 
razão, além da produção teórica e das próprias instituições políticas, também consideramos movimentos sociais e organizações da sociedade civil como fontes relevantes para pesquisas no âmbito da Teoria do Estado sobre alternativas para reformas institucionais.

Da perspectiva epistemológica que defendemos para a Teoria do Estado resulta um trabalho simultaneamente técnico e político. É técnico porque compreende a análise de alternativas institucionais orientada pelos critérios de coerência e funcionalidade, e baseada em tendências empiricamente verificadas. Mas também é político, porque as estruturas de poder e os procedimentos políticos decisórios não são neutros, podem favorecer a manutenção do status quo ou sua transformação, envolvendo, portanto, conflitos de interesses. Assim, uma pesquisa neste campo deve ser objetiva, mas é impossível que seja politicamente neutra: objetividade e neutralidade do conhecimento não se confundem. ${ }^{14}$ (B. S. SANTOS, 2003). Isso implica confrontar a estratégia hegemônica de despolitizar os assuntos públicos e as perspectivas teóricas que, consciente ou inconscientemente, lhe dão sustentação. (RANCIÈRE, 2014).

Para concluir a discussão sobre a perspectiva metodológica que propomos para a Teoria do Estado, passamos a aprofundar o que se entende por "mapeamento crítico de alternativas". Em síntese, o mapeamento consiste na observação crítica das instituições e projetos institucionais, a análise de suas falhas, limites, qualidade e potenciais, buscando-se alternativas para seu aperfeiçoamento (UNGER, 1996).

Encontramos em Unger (1996, 1999, 2001, 2015) e na sua ideia de "experimentalismo democrático" as diretrizes para o desenvolvimento dos "mapeamentos": (1) a urgência da imaginação de novos arranjos institucionais para enfrentarmos os problemas de nosso tempo exige a superação da prostração intelectual e política diante da suposta ausência de alternativas, a qual decorre do "fetichismo institucional" e do "fetichismo estrutural"; (2) as transformações institucionais não precisam assumir um caráter global e revolucionário, pois podem ocorrer por meio da somatória de pequenas mudanças orientadas pela

de "epistemologias do sul" (diversidade de conhecimentos produzidos no âmbito do "Sul geopolítico global"), o qual se apoia em três premissas fundamentais: (1) "a compreensão do mundo é muito mais ampla do que a compreensão ocidental do mundo"; (2) "a diversidade do mundo é infinita", mas é "desperdiçada porque, devido ao pensamento hegemônico que temos, permanece invisível", de maneira que precisamos não só de alternativas, mas de "um pensamento alternativo de alternativas"; (3) "esta grande diversidade do mundo pode e deve ser ativada, assim como transformada teoricamente e praticamente de muitas maneiras plurais, não pode ser monopolizada por uma teoria geral". Além disso, é necessária uma maior abertura para o diálogo entre teoria e prática, inclusive com a adoção de uma postura de acordo com a qual a teoria "aprende com a prática", com as lutas sociais, e seu papel fundamental consiste em buscar "aprofundar alguns elementos da prática", sobretudo no sentido de trazer "elementos de comparação com outras experiências de emancipação".

${ }^{14}$ Cf. Tojal, 1997. 
ideia de "reforma radical", e a partir da identificação das "oportunidades transformadoras"; (3) para tanto, a imaginação institucional deve partir das circunstâncias históricas, tomadas como condicionantes e não como impedimentos absolutos, para então construir ideias programáticos realistas; (4) os modelos teórico-normativos não devem ser dissociados da análise empírica na avaliação e projeção de instituições; (5) as propostas de experimentação democrática não são neutras; (6) é preciso combinar a mobilização social com a participação institucionalizada por meio de desenhos ousados e inclusivos; (8); as instituições não devem ser desenhadas para um cidadão idealizado, mas considerar os sujeitos reais com suas limitações.

Para nos referirmos ao caso específico da pesquisa da qual derivam estas reflexões metodológicas, em um mapeamento crítico de alternativas de reformas institucionais no âmbito da governança financeira global, as diretrizes apresentadas por Unger $(1996,1999,2001,2015)$ indicam, em primeiro lugar, que só será possível encontrar alternativas se condições de natureza geopolítica e econômica forem consideradas adequadamente como condicionantes e não como determinantes (superação do "fetichismo estrutural"), bem como que os modelos institucionais que costumamos empregar para a democracia no âmbito nacional (representação, eleição etc.) não sejam considerados os únicos possíveis para as instituições de GFG (superação do "fetichismo institucional"). A GFG não apresenta um sistema estruturado, hierarquizado, com coordenação central, mas é rizomática, complexa, com múltiplos níveis. Assim, propostas de reforma global apresentam poucas chances de prosperar, podendo ser mais eficiente a soma de pequenas reformas, as quais podem ser articuladas e orientadas por uma perspectiva de mudanças radicais. Sendo um campo que compreende questões técnicas extremamente complexas, os desenhos institucionais para reforma da GFG devem considerar as limitações dos cidadãos para participarem efetivamente desses processos. Além de formas inovadoras e historicamente fundadas de participação institucional mais ampla na GFG, é fundamental que exista alguma forma de mobilização social, como uma "esfera pública financeira global". Enfim, destacamos que as pesquisas sobre alternativas para reforma institucional na GFG devem combinar a análise empírica com a de modelos teóricos de democracia global.

Com fundamento nesses pressupostos, em termos operacionais, o mapeamento institucional pode ter como primeiro passo a revisão bibliográfica orientada pelas questões formuladas na definição do problema de pesquisa. A coleta e a análise do material bibliográfico devem ser desenvolvida da maneira mais abrangente e sistemática possível, compreendendo tanto obras de referência previamente conhecidas, como a verificação de publicações recentes em revistas especializadas, inclusive valendo-se de buscas em bases de dados a partir de palavras-chave pertinentes ao objeto da pesquisa. Entretanto, a revisão bibliográfica não é suficiente, deve ser acompanhada de coleta e análise de 
documentos bem como, se for o caso, a utilização de outros métodos empíricos, conforme o escopo da pesquisa. No que se refere às fontes de alternativas para reformas institucionais, não se limitam à produção teórica, sendo especialmente relevantes os projetos implementados ou em debate nas próprias instituições políticas (parlamentos, governos, organizações internacionais etc.), como também ideias e propostas defendidas por organizações não-governamentais e movimentos sociais, as quais, porém, em geral, apresentam pouca elaboração em termos de desenhos jurídico-institucionais. As propostas mapeadas devem ser sistematizadas em quadros analíticos e, posteriormente, submetidas a uma análise crítica que considere tanto critérios normativos (por exemplo, conceitos normativos de democracia) como empíricos (adequação e plausibilidade em face do diagnóstico, por exemplo, sobre o déficit democrático da instituição ou do sistema de instituições objeto da pesquisa).

Com este ensaio, esperamos contribuir com o debate em curso sobre as raízes da Teoria do Estado e novas perspectivas para a disciplina em um contexto de múltiplas crises e de exigência de reformas institucionais no Estado e no sistema de organizações internacionais e transnacionais de governança global, tanto no que e refere ao à ampliação do escopo de seu objeto como a seu método, particularmente a partir da abordagem do "mapeamento institucional". A Teoria do Estado não apenas conserva sua relevância científica no contexto contemporâneo, como apresenta uma perspectiva epistemológica singular para a compreensão dos problemas da institucionalização jurídica do poder.

\section{REFERÊNCIAS BIBLIOGRÁFICAS}

AGNÉ, Hans. The autonomy of globalizing states: bridging the gap between democratic theory and international political economy. International political science review, v. 32, Issue 1, p. 43-60, 2011.

BELFRAGE, Claes; WORTH, Owen. Critical international political economy: Renewing critique and ontologies. International politics, n. 49, n.2, p. 131-135, mar. 2012.

BOSWELL, Terry; CHASE-DUNN, Christophe. Transnational Social Movements and Democratic Socialist: Parties in the Semiperiphery - On to Global Democracy. In: CHASE-DUNN, Christopher; BABONES, Salvatore J. Global social change Historical and Comparative Perspectives. Baltimore: The Johns Hopkins University Press, 2006, p. 317-335. 
BRUNET, Emiliano. Estado, Poder Político e Direito em uma Época de Mudanças: por que ler Gramsci? Revista Estudos Institucionais. V.7, N.3, 880-907, set./dez., 2021.

BUCCI, Maria Paula Dallari. A Teoria do Estado entre o jurídico e o político. In: BUCCI, Maria Paula Dallari; GASPARDO, Murilo. Teoria do estado: sentidos contemporâneos. São Paulo: Saraiva, 2018. p. 27-74.

CALLINICOS, Alex. Equality. Cambridge: Polity, 2000.

COX, Robert W. Critical Political Economy. In: COX, Robert W. et alii.

International political economy - Understanding Global Disorder, London: Zed Books, 1995. p.31-45.

COX, Robert. Social Forces, States and World Orders: Beyond International Relations Theory, Millenium: Journal of International Studies, v. 10, n. 2, p. 126$155,1981$.

DALLARI, Dalmo de Abreu. Elementos de Teoria Geral do Estado. São Paulo: Saraiva, 2013.

DRYZEK, John S.; HONIG, Bonnie; PHILLIPS, Anne. Introduction. In: DRYZEK, John S.; HONIG, Bonnie; PHILLIPS, Anne (ed.). The oxford handbook of political theory. Oxford: Oxford University Press, 2006, p. 3-41.

ELKIM, Stephen L. Political Theory and Political Economy. In: DRYZEK, John S., HONIG, Bonnie; PHILLIPS, Anne (ed.). The oxford handbook of political theory. Oxford: Oxford University Press, 2006, p. 792-809.

GASPARDO, Murilo. Democracia e governança financeira global. São Paulo: Alameda, 2021

HALE, Thomas; YOUNG, Kevin; HELD, David. Gridlock - Why global cooperation is failing when we need it most. Cambridge: Polity, 2013.

HELD, David. Models of Democracy. Cambridge: Polity, 2006.

HELLER, Herman. Teoría del estado. Trad. Luis Tobío. México: Fondo de Cultura Económica, 1942. 
HETTNE, Björn. Introduction: The International Political Economy of Transformation. In: COX, Robert W. et al. International political economy Understanding Global Disorder. London: Zed Books, 1995. p.1-30.

JELLINEK, Georg. Teoría general del estado. Tradução de Fernando de los Rios. Buenos Aires: Albatros, 1954.

KELSEN, Hans. Teoría general del estado. Tradução de Luís Legaz Lacambra. México: Nacional, 1973.

LAWFORD-SMITH, Holly. Understanding Political Feasibility. The journal of political philosophy, v. 21, n. 3, p. 243-259, 2013.

LEWANDOWSKI, Henrique Ricardo. Globalização, regionalização e soberania. Tese (Professor Titular na área de Teoria Geral do Estado) - Faculdade de Direito da Universidade de São Paulo. São Paulo: Universidade de São Paulo, 2002.

MITTELMAN, James H. What is Critical Globalization Studies? (2004) In: MITTELMAN, James H. Contesting global order - Development, Global Governance and Globalization. London and New York: Routledge, 2011. p. 139149 .

RANCIÈRE, Jacques. Ódio à democracia. Tradução de Mariana Echalar. São Paulo: Boitempo, 2014.

RANIERI, Nina Beatriz. Teoria do estado: do Estado de Direito ao Estado Democrático de Direito. Barueri: Manole, 2013.

REALE, Miguel. Teoria do Direito e do Estado. São Paulo: Martins, 1960.

SANTOS, Boaventura de Souza. Introducción: las Epistemologías del Sur. In: CIDOB (org.), Formas-Otras. Saber, nombrar, narrar, hacer. Barcelona: CIDOB Ediciones, 2011 - 2012, p. 9 - 22. Disponível em: < http://www.boaventuradesousasantos.pt/media/INTRODUCCION_BSS.pdf $>$. Acesso em: 30/07/2014.

SANTOS, Boaventura de Sousa. Para além do Pensamento Abissal: das Linhas Globais a uma Ecologia de Saberes. In SANTOS, Boaventura de Sousa, MENESES, 
Maria Paula (org.). Epistemologias do Sul. 2ª ed. Coimbra: Almedina, 2010, p. 23 -71 .

SANTOS, Boaventura de Sousa. Poderá o direito ser emancipatório? Revista crítica de ciências sociais, Coimbra, n. 65, p. 3-76, maio 2003.

STUCHI, Carolina Gabas. Contribuição para uma teoria realista do Estado Brasileiro. In: BUCCI, Maria Paula Dallari; GASPARDO, Murilo. Teoria do estado: sentidos contemporâneos. São Paulo: Saraiva, 2018. p. 135-165.

TOJAL, Sebastião Botto de Barros. Teoria geral do estado: Elementos de uma nova ciência social. Rio de Janeiro: Forense, 1997.

UNGER, Roberto Mangabeira. Democracia realizada - A alternativa progressista. Tradução de Carlos Graieb, Márcio Grandchamp e Paulo César Castanheira. São Paulo: Boitempo, 1999.

UNGER, Roberto Mangabeira. False Necessity - Anti-necessitarian Social Theory in the Service of Radical Democracy. London/New York: Verso, 2001.

UNGER, Roberto Mangabeira. The Critical Legal Studies Movement - Another Time, a Great Task. London/New York: Verso, 2015.

UNGER, Roberto Mangabeira. What Should Legal Analysis Become? London/New York: Verso, 1996.

WALDRON, Jeremy. Political Political Theory: An Inaugural Lecture. The journal of political philosophy, v. 21, n. 1, p. 1-23, 2013.

WIENS, David. Prescribing Institutions Without Ideal Theory. The journal of political philosophy, v. 20, n. 1, p. 45-70, 2012. 